\title{
DECENTRALIZATION FOR REGIONAL INFRASTRUCTURE DEVELOPMENT IN EASTERN GEORGIA
}

\author{
Kardava T. \\ Georgia Tbilisi, \\ Caucasus University,PHD Student at Caucasus School of Economics; \\ Georgian Technical University, Lecturer; \\ Regional Coordinator for Eastern Georgia at Municipal Development Fund of Georgia
}

DOI: https://doi.org/10.31435/rsglobal_ijite/01062018/5652

\section{ARTICLE INFO}

Received 06 April 2018

Accepted 03 May 2018

Published 01 June 2018

\section{KEYWORDS}

\section{Region,}

Infrastructure,

Decentralization,

Strategy,

Development

\begin{abstract}
This article is about analyzing and decentralization strategy in Eastern Georgia. An ongoing process of decentralization puts on the agenda the regional infrastructure planning, development and optimization. The political importance is given to the creation of the regional infrastructure development strategy.

Prior to that, it is important to note the existing regional infrastructure. It is not only about traditionally the highland regions, but the general municipalities, development potentials and perspectives. The above mentioned is particularly relevant to find that all municipalities have their own niche, that is attractive to the tourists and will be able to develop as well as maintain population in rural areas.
\end{abstract}

(c) 2018 The Author.

Problem statement. The reality in the separate regions of Georgia is a significant indicator of economic, political and social strength of the country. That's why the correct analysis and problem solving are important factors.

Georgia's regions face significant challenges, they do not have an equal opportunities for development. In order to achieve maximum productivity and efficiency, optimal use of each region's potential development and proper resource allocation is necessary. The causes of inequality in the regions of Georgia are unequal distribution of the population of Georgia. Most of them live in municipal centers and in areas where economic activity levels are relatively high. Inequality between the regions' development levels also contributes to their natural geographical features, the differences in industrial, tourism, agricultural and social infrastructure development.

The measures taken by the government of Georgia are not enough. They periodically carry out the policy toward balancing territorial development. Due to the fact that the Self-governing entities have different revenues, the state implements local budgets with equitable transfer, which partly provides an equal level of living in local self-governing units. The government of Georgia carries out various targeted programs, taking into consideration the interests of the self-governing entities and financing projects (especially infrastructural projects), both through the state budget and international donor organizations, including credits and grants. The Ministry of Regional Development and Infrastructure of Georgia is the supervisory body responsible for planning and implementation of regional policy and coordinates the projects implemented by the government of Georgia through the "Funded Projects to be implemented in the Georgian Regions". The Ministry of Regional Development and Infrastructure, together with subordinated departments under its control, and many other state structures, carry out many infrastructural projects in the regions, however regrettably they are not enough. Also, the Government of Georgia spends lots of time, energy and recourses in preparing numerous short term or long term strategies for each regions, but unfortunately it is impossible to execute. There is no master state plan for the regional development, except for regional development projects.

In my observation, the frequent change of the government, which changes the priorities alongside with the change of the staff, often causes delays and interruptions of the regional development projects. Sadly, many infrastructural projects are planned to be chaotic, they are created according to the "specific" people's enjoyment/priorities and not necessarily due to specific urgent needs. 
As for the already prepared strategies (which are quite costly to prepare), and often are posted on the Ministry's and Governors' online websites, if they are not enforced for the development of the specific municipalities, they will stay as decorations and words on the paper.

As for the municipality's development strategy, it is important to first interpret the definition of it, which is quite widespread in Georgian politics, even in the household and in the household vocabulary.

The word strategy, according to the dictionary of civil education, has few definitions:

1. Social, the art of planning and directing political operations; and

2. Art of planning military operations.

Political science has brought the term from military science to unlike tactics that involve fighting, the strategy is art of warfare. In this sense, the strategy is a long-term plan which, apart from direct military operations, implies all the components necessary for warfare (economic, communication, cultural, etc.). consideration and planning. Furthermore, they differentiate between "strategy" and "big strategy". A great strategy is associated with world war and global conflicts. The great strategy of the Cold War was mainly elaborated by the superpowers, the Soviet Union and the United States. The term strategy involves political planning of a party, political group or even longterm action plan. Many organizations in Georgia whether it is state or private agencies, often create strategies, many resources are spent and presentations are present, but the most disappointing is that in most cases these strategies remain unenforced and unimplemented on daily basis.

Investment processes and direct foreign investments are of great importance for the country's economic progress. Based on the above, it is necessary to take into consideration the diverse range of developing world and to develop a regional development strategy that is suitable to the country's budget and will also attract donors to the competitive environment with the necessary and desirable conditions.

In November 2013, the Government of Georgia has prepared a project "Georgia's SocioEconomic Development Strategy, Georgia 2020", in which "the Government of Georgia aims to implement the economic policy that will ensure sustainable development of the country. Also, the openness and attractiveness of the country for foreign investments will be ensured in parallel with financial openness, integration into international financial markets and at the same time reducing the country's financial risks.

Also, the Strategy points to the new role of the government, encouraging the private sector to attract investments and create a fair and protected business environment. Its task is to promote business development through innovations and entrepreneurial skills, which is the main driving force of the country's economic growth.

The government's strategy determines a number of priority directions, including one of the most important issues in the development of investment and business environment, the Government believes that it is necessary to continue to improve the entrepreneurial and investment environment.

The Ministry of Regional Development and Infrastructure of Georgia together with various stakeholders will develop regional development strategies for years.

As for now, the Regional Development Strategy 2014-2021 is prepared for guidance to the regions. The document outlines the potentials of the regions as well as the problems that should be prioritized and solved within next years. The strategy will be successful if the problems described in the document by the regions can be minimized.

The model, that is oriented towards economic growth, has enabled Georgia to significantly increase the income of local population per capita. Currently, regional investments at regional and municipal level are prioritized.

The government also continues to support the private sector to create economic growth and job opportunities, to continue the gradual process of acquiring private sector trusts. The government of Georgia has developed a framework for regional development in order to attract private investors in various sectors of regional importance as tourism and agriculture. However, there are still some problems in terms of lack of physical and institutional capabilities that hinder private investment in areas with economic development.

It is an appropriate to consider the example of Mtskheta-Mtianeti regional development 20142021 strategy.

Mtskheta-Mtianeti region is an administrative-territorial arrangement. Mtskheta, Dusheti, Tianeti and Kazbegi municipalities and its borders coincide with the action area of the state attorneygovernor in these municipalities. Their strategy reflects the existing situation and the mechanisms to increase the development and promotion of the development of the region.

The above-mentioned strategy includes all the central, regional and local priorities that exists throughout the region and all the resources that will be used in this direction. The strategy covers the 
objectives and priorities of the development of economic, social and environmental projects, only lacks execution in reality.

The center of the region is the city of Mtskheta, which was the oldest capital of Georgia and is now functioning as an important religious, cultural and tourist center of the country. The distance between the center and the capital of Georgia - Tbilisi is only $24 \mathrm{~km}$, which is another additional contributing factor for development and success.

Mtskheta-Mtianeti region has a great potential in tourism development. All four municipalities of the region are distinguished with great historical past, monuments, customs and traditions. Special significance is Mtskheta, which is protected by UNESCO. Interesting for tourists is a beautiful landscape and the mountainous region which has a great potential to develop different types of tourism: cultural, pilgrimage, archeological, adventure, ecotourism, agro-tourism, mountain skiing, cognitive tourism, extreme tourism and etc.

Mtskheta and Kazbegi municipalities are particularly notable as of top destinations for tourists. The interest in these two towns has always existed, which has led to state and local projects. Infrastructural development and rehabilitation is underway in Mtskheta and Borjomi. One of the main goals of this project are tourism development, creating new jobs and increasing local revenues. The ongoing infrastructure development in the region has led to increase of domestic and foreign tourists, increase of local guest houses and other tourist services. Also, construction of luxurious hotels in recent years has been observed.

However, the level of living is quite low in the region. In 2014, 9,933.00 families were registered for the governments' social assistance program. In the region, 18,585 people are pension recipients, which is $9,12 \%$ of the population and significantly lower the country's average percentage rate $(19.05 \%)$. On many occasions, it has come to my attention that local people find it difficult to find a cheap worker in the villages because these families prefer to have social assistance over a real job. Therefore, granting socially vulnerable status has been a hindrance for many people to find a place to work and earn better income compare to a person with the social assistance.

Traditionally, the share of self-employed significantly prevails in the employee. The absolute majority of the village population is engaged in labor activity at their own farms. The low level of employment is associated with the lack of jobs. Unemployment also contributes to the lack of qualified personnel. Often qualified personnel flow from the region to the capital.

According to economic activity in Mtskheta-Mtianeti region, the share of the product is mainly produced from industry, followed by construction, agriculture, trade, communication and so forth.

Motorways (including the inland roads of the country) occupy $476,6 \mathrm{~km}$ in the region. Including international importance - $172.3 \mathrm{~km}$, the national importance - 460,3 km, and the local significance - more than $800 \mathrm{~km}$.

It should be noted that the asphalt or concrete cover is not covered by a large part of the local roads of local importance that connects municipal centers and relevant settlements. Landslide and mudflows are permanently damaging the roads, which is why it is impossible to communicate with many settlements during the winter snow. Majority of the internal roads of the municipality are regulated. Particularly acute problem is the roads connecting the villages of Khevsureti, Gudamakari and Mtiuleti, which are difficult to go in the summer conditions and are closed in the winter, which causes them to cut off from the municipality center. I would like to note in the positive context that one of the important Roshka-Arkhyeli road project of the Municipal Development Fund of Georgia is aimed in giving the villages (Roshka, Arkhiyeli, Chimgha, Amght) to Pirikiti and Khevsureti villages in the regional center (Dusheti) and other regions of the country to connect with cities. It should be noted that the above mentioned villages have no access to the car and the population is moved only by pedestrian trails.

Mtskheta-Mtianeti region is also a significant loss of drinking water due to the old and damaged water system. Most of the populated areas are not secured by a sewerage network. Most of the networks that are currently functioning require reconstruction and renewal. About $60-70 \%$ of the runoff is lost from the sewage network which causes pollution of groundwater, which negatively affects the health of beneficiaries.

Despite numerous efforts and continued work in the waste management direction in the region and in its municipalities, except for the administrative centers, it is not properly managed to take away the waste and the problem of landfills is not solved.

Natural disasters are also frequently observed in the region, such as earthquakes, floods, landslides, mudflows, avalanches, drought. Demographic changes, unplanned urbanization, chaotic development, insufficient control over safety norms, socioeconomic inequality, environmental degradation, climate change and lack of planning and realization of preventive measures on the 
background of the above are the causes of increased intensity and frequency of catastrophes. All levels of state management. These problems require an active approach and quick response to avoid natural disasters that are already characteristic for this region. All possible natural threats and risks should be considered.

The "Devdorac landslide", which was occurred in 2014, has shown that reducing the risk of disaster is a multi-faceted, complex issue that needs to be promoted at the political and legislative level. Relevant scientific knowledge, planning of correct development, strict control over legislation, effective preparation and response mechanisms for disaster and public awareness of these issues.

Strategic views, priorities and proposals developed for sustainable development of MtskhetaMtianeti are based on the resources of the region and multilateral analysis of its sectoral development, relevant situational and factual diagnostics.

According to the region's strategy, the goals of Mtskheta-Mtianeti region for 2021 are as follows:

1. Establishment of the innovative (cluster) sustainable development of the region; business;

2. Development of investment policy and promotion of export-oriented small and medium

3. Sustainable development of agriculture tourism;

4. Promote development of the innovative sector of economy and attract investments;

5. Improve access to education, culture and sports;

6. Improve access to health and social services;

7. Improvement of transportation services;

8. Development of social and utility infrastructure;

9. Improvement of regional and municipal governance and self-government; and

10. Environmental Protection, Maintaining sustainable ecological balance and minimizing environmental impacts.

Conclusions. It is important to create a strategy that will support and return the Georgian population to the rural regions. It should be done with the involvement of locals depending on their needs and priorities and based on decentralization principles.

It is also necessary to encourage the people who will be involved in the decision-making process and support civil awareness of ongoing projects in the region.

At the end, I would like to offer the following recommendations to the government and the municipalities:

- to follow the principle of subsidiarity;

- to accelerate the process of decentralization;

- to improve the legislation, improve and harmonize with international agreements and obligations;

- to enhance the finances as well as property and independence of regions;

- to develop socio-economic development of regions;

- to develop a long-term development strategy for regions that will be the main guide and axis for all regions.

To develop a master urban planning plan and especially, for the strategically important municipalities in order to stop chaotic constructions;

To set penalties, monitor and enforce the city's maintenance.

I believe that my recommendations will be helpful and inevitable for the decentralization projects in Georgia. The Regional and infrastructure improvement is leading to the development and success of the country.

\section{REFERENCES}

1. The Government of Georgia. 2015. Georgia's Socio-Economic Development Strategy Georgia 2020. Tbilisi.

2. Ministry of Regional Development and Infrastructure of Georgia. Mtskheta-Mtianeti development strategy for 2014-2021. Tbilisi, GIZ.

3. Ministry of Regional Development and Infrastructure of Georgia - http://www.mrdi.gov.ge/

4. What is the word strategy - http://www.etaloni.ge/geo/main/index/923

5. Evgenidze N. Infrastructure Projects and Economic Growth http://www.radiotavisupleba.ge/content/ekonomikuri-zrda/26587356.html 